\title{
Solitary parotid duct sialolith in a patient with Sjörgren's syndrome: Report of a case
}

\author{
Wan Ahmad Kamil WN, Hassan S, Rahman FA, Burhanuddin NA, Goh YC, Kadir K, Siar CH* \\ Department of Oral and Maxillofacial Clinical Sciences, Faculty of Dentistry, University of Malaya, 50603 \\ Kuala Lumpur, Malaysia.
}

\begin{abstract}
Sjörgren's syndrome is an uncommon chronic autoimmune disorder that affects exocrine glands. Sialolithiasis is an obstructive salivary gland disease which is also uncommon in the parotid salivary gland. The existing literature has documented the occurrence of multiple calcifications within the parenchyma of the parotid glands in patients with Sjörgren's syndrome. This report describes the first case of right parotid duct solitary sialolith formation in a 64 year old female patient with Sjörgren's syndrome. Whether the salivary stone encountered in this case represents an oral manifestation of Sjörgren's syndrome or is just a co-incidental finding was discussed.
\end{abstract}

Keywords: Sialolithiasis, Sjörgren's syndrome, diagnosis, management

\section{Introduction}

Sjörgren's syndrome is a chronic autoimmune disease due to progressive lymphocytic infiltration and subsequent destruction of exocrine glands (1). Although the underlying cause is unknown, mounting evidence indicates that both the innate and acquired immune systems are co-stimulatory in the pathogenesis of this disease $(1,2)$. In the ACR/EULAR classification, Sjörgren's syndrome is subclassified into primary and secondary forms, based on the absence/presence of an underlying systemic autoimmune disease (3). The clinical presentation in both forms of Sjörgren's syndrome typically consists of dry mouth (xerostomia) and dry eyes (kerato-conjunctivitis sicca).

Sialolithiasis, also termed salivary calculi or salivary stone formation, is due to deposition of calcium salts around a central nidus which may consist of altered salivary mucins, desquamated epithelial cells, bacteria, foreign bodies, or products of bacterial decomposition (4-6). It is the most common cause of salivary gland obstruction. Sialolithiasis is rare in the parotid duct (Stensen's duct) with occurrence rate of $5 \%$ to $15 \%$ compared to the submandibular gland where the prevalence is considerably higher ( $85 \%$ to $95 \%)$. Sialoliths are composed of varying ratios of organic and inorganic substances (4, 6 ). The chemical composition consists mainly of microcrystalline apatite or whitlockite. Apatite is the most prevalent component present throughout the stone, while whitlockite is mainly found in the core $(4,5)$. Submandibular stones are composed of $82 \%$ inorganic and $18 \%$ organic material, whereas parotid stones are composed of $49 \%$ inorganic and $51 \%$ organic material (6).

Sialolithiasis occurring in association with Sjörgren's syndrome is uncommon. Multiple calcifications involving the parenchyma of parotid salivary gland have been described in the literature (7-9). In this report, we presented a case affecting 
the right Stensen duct in order to document this rare occurrence.

\section{Case Report}

A 64-year-old female patient presented to the Oral Medicine Clinic, Faculty of Dentistry, University of Malaya with a one month history of recurrent swelling and associated pain in the area of her right parotid salivary gland. The patient experienced throbbing pain in her right cheek region over the area of parotid salivary gland. The other complaints were dry mouth and dry eyes. Her past medical history included treatment for coronary heart disease at the National Heart Institute Malaysia and hypertension under control with medications (Flavic and Bisoptrolol). The patient was also previously diagnosed with Sjörgren's syndrome and was prescribed medications from 2009 to 2011. She gave a history of allergy to sulphur which caused skin rashes. The patient further informed that there is a strong family history of autoimmune diseases that included rheumatoid arthritis and Raynaud's disease. Informed consent was obtained from this patient.

At initial presentation, she described her pain as throbbing in nature especially when eating and the pain occasionally disturbed her sleep pattern. There is no obvious swelling of her right face extraorally. Intraorally, bimanual palpation revealed inflammation near the opening of her right Stensen's duct with reduced salivary flow from the orifice. A stone-like mass which was white yellowish in colour could be seen and palpated near the orifice (Figure 1A).
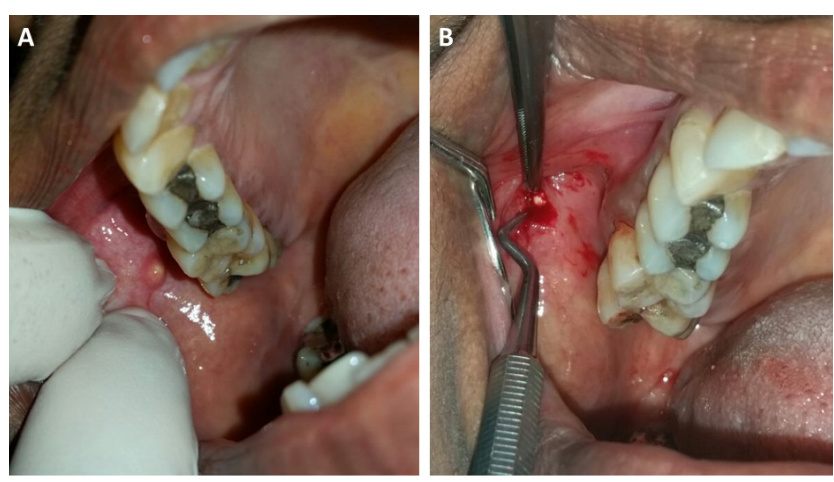

Figure 1: (A) A stone-like mass which is white yellowish in colour at the orifice of right parotid duct. (B) Surgical removal of the sialolith via an intraoral approach.

CT scan imaging revealed a small radiopaque lesion at right parotid duct opening (not available). On the basis of clinical examination and imaging findings, a diagnosis of sialolithiasis of the right Stensen's duct was made. Surgical removal of the sialolith with an intraoral approach was conducted under local anaesthesia (Figure 1B).

The sialolith measured $5 \mathrm{~mm}$ in diameter (Figure 2A). Patient was reviewed after a week, the surgical area had healed well (Figure 2B) and she was advised to continue eating sour food to stimulate salivary flow.
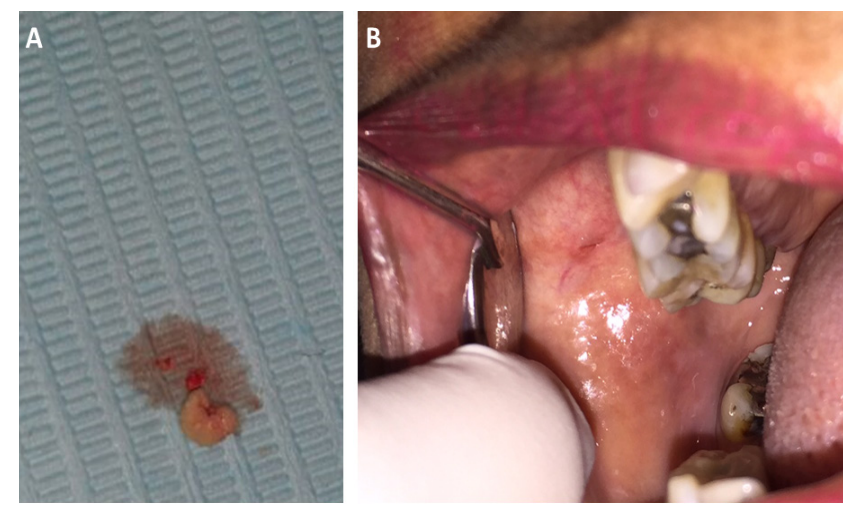

Figure 2: (A) Gross specimen of sialolith measures approximately $5 \mathrm{~mm}$ in diameter. (B) Post-operative evaluation at one week shows the site has completely healed.

\section{Discussion}

The patient in this case presented with complaints of pain and swelling over the right parotid salivary gland. It is well-recognized that patients who have sialolithasis typically present with unilateral facial swelling and pain, which is worsened by eating when salivary flow is forced against an obstruction. The pain usually last for no more than two hours. Sometimes, swelling is accompanied by an episode of salivary colic defined as an acute, lancinating pain that disappears after 15 or 20 minutes (5-7). However, sialolithiasis with salivary gland obstruction can mimic more commonly occurring illnesses such as viral or bacterial infection, tumours of the salivary glands, and infection of the surrounding soft tissues or dental structures. In some cases, the sialolith may cause stasis of the saliva, leading to bacterial contamination of the parenchyma of the gland, and clinical infection, with pain and swelling of the gland. Long-term obstruction in the absence of infection can lead to atrophy of the gland with resultant lack of secretory function and eventual fibrosis (4). If sialadenitis develops, pain and erythema typically worsen and they may develop systemic symptoms to include fevers and chills. Occasionally, the sialolith may be palpable along the course of the duct in the face or the floor of the mouth, which feels like a small pebble $(4,6)$.

We are unclear whether the patient in this report represents a case where the sialolith in the Stensen duct is a co-incidental finding or is indeed part of the 
many manifestations/complications associated with Sjörgren's syndrome $(7,8)$. The aetiological factors for sialolith formation are still poorly-understood, but saliva retention due to anatomical considerations, and saliva composition, are believed to be important contributing factors (4). In Sjörgren's syndrome, the ongoing lymphocytic infiltration and chronic inflammation associated with destruction of secretory acinar units and sialectasia are factors conducive for stasis of salivary flow and salivary stone formation (79). The traditional theories suggest that the formation of sialoliths occur in two phases: 1. Formation of a central core and 2. A layered periphery. The central core is formed by the precipitation of salts, which are bound by certain organic substances. The second phase consists of the layered deposition of organic and non-organic material. Submandibular sialoliths are thought to be formed around a nidus of mucus, whereas parotid sialoliths are thought to be formed around a nidus of inflammatory cells or a foreign body $(5,6)$. Salivary calculi are usually small and measure from $1 \mathrm{~mm}$ to less than $1 \mathrm{~cm}$. They rarely measure more than $1.5 \mathrm{~cm}$. Mean size is reported as 6 to $9 \mathrm{~mm}(5)$.

Once a diagnosis of sialolithiasis is made, effective treatment of the sialolith depends on the location of the stone, and is accomplished by extraoral or intraoral surgical removal of the sialolith (10-12). Removal of the affected salivary gland and its associated duct may also be necessary (10). Typically, calculi $<2 \mathrm{~mm}$ in diameter can be treated without surgical intervention. Initial treatment options include oral analgesia (nonsteroidal antiinflammatory drugs or opiates in some cases), hydration, local heat, gland massage, sialogogues (ie, sour candy) to promote ductal secretions, and discontinuation of anticholinergic medications (11, 12).

\section{Conclusion}

In conclusion, this case report serves to illustrate that the clinician/surgeon should be aware that parotid duct solitary sialolith formation may occur in patients with Sjörgren's syndrome. Current evidence suggests that multiple calcifications within the parenchymatous content of the parotid salivary gland is not an uncommon finding in Sjörgren's syndrome whereas sialolith formation in the Stensen duct proper is relatively rare.

\section{Acknowledgements}

The authors would like to express their thanks to the Oral Surgery and Oral Medicine Clinic nurses for their assistance and support. This study is partly funded by FP032-2015A.

\section{Conflicts of interest}

The authors declare no conflicts of interest.

\section{References}

1. Bayetto K, Logan RM. Sjögren's syndrome: a review of aetiology, pathogenesis, diagnosis and management. Aust Dent J. 2010; 55 Suppl 1:39-47.

2. Segal BM, Nazmul-Hossain ANM, Patel K, Hughes P, Moser KL. Rhodus NL. Genetics and genomics of Sjorgren syndrome: research provides clues to pathogenesis and novel therapies. Oral Surg Oral Med Oral Pathol Oral Radiol Endod 2011; 111:673-80.

3. Shiboski $\mathrm{CH}$, Shiboski SC, Seror R, Criswell LA, Labetoulle M, Lietman TM,Rasmussen A, Scofield H, Vitali C, Bowman SJ, Mariette $X$. International Sjögren's syndrome criteria working group. 2016 American College of Rheumatology/European League against Rheumatism classification criteria for primary Sjögren's syndrome: A consensus and datadriven methodology involving three international patient cohorts. Ann Rheum Dis 2017;76:9-16.

4. Kraaij S, Karagozoglu KH, Forouzanfar T, Veerman EC, Brand HS. Salivary stones: symptoms, aetiology, biochemical composition and treatment. Br Dent J 2014; 217: E23.

5. Im YG, Kook MS, Kim BG, Kim JH, Park YJ, Song HJ. Characterization of a submandibular gland sialolith: micromorphology, crystalline structure, and chemical compositions. Oral Surg Oral Med Oral Pathol Oral Radiol. 2017; 124: e13-e20.

6. Torres-Lagares D, Barranco-Piedra $S$, Serrera-Figallo MA, Hita-Iglesias P, MartínezSahuquillo-Márquez A, Gutiérrez-Pérez JL. Parotid sialolithiasis in Stensen's duct. Med Oral Patol Oral Cir Bucal 2006;11:E80-4.

7. Shimizu M, Yoshiura K, Nakayama E, Kanda S, Nakamura S, Ohyama Y, Nakamura N. Multiple sialolithiasis in the parotid gland with Sjögren's syndrome and its sonographic findings - Report of three cases. Oral Surg Oral Med Oral Pathol Oral Radiol Endod 2005; 99: 85-92.

8. Konstantinidis I, Paschaloudi S, Triaridis S, Fyrmpas G, Sechlidis S, Constantinidis J. Bilateral multiple sialolithiasis of the parotid gland in a patient with Sjögren's syndrome. ACTA Otorhinolaryngol Italica 2007;27:41-4.

9. Izumi M, Kise $Y$, Murata K, Murata A, Nkayama M, Ariji Y, Naitoh M, Ariji E. Multiple calcifications within the parotid gland of patients with 
Sjörgren's syndrome. Oral Sc Int 2013; 10: 28- Corresponding author: 32.

10. Ugga L, Ravanelli M, Pallottino AA, Farina D, Maroldi R. Diagnostic work-up in obstructive and inflammatory salivary gland disorders. Acta Otorhinolaryngol Ital 2017; 37: 83-93.

11. Kopeć T, Wierzbicka M, Szyfter W, Leszczyńska $M$. Algorithm changes in treatment of submandibular gland sialolithiasis. Eur Arch Otorhinolaryngol. 2013;270:2089-93.

Chong Huat Siar

Department of Oral and Maxillofacial

Clinical Sciences,

Faculty of Dentistry, University of Malaya,

50603 Kuala Lumpur,

Malaysia

Phone: (603)7967-4859; Fax: (603)7967-4534,

e-mail: siarch@um.edu.my

12. Capaccio P, Torretta S, Pignataro L, Koch M. Salivary lithotripsy in the era of sialendoscopy. Acta Otorhinolaryngol Ital 2017;37:113-21. 